\title{
Downregulation of eukaryotic initiation factor 4A1 improves radiosensitivity by delaying DNA double strand break repair in cervical cancer
}

\author{
SHANHUI LIANG ${ }^{1,2}$, XINGZHU JU ${ }^{1,2}$, YUQI ZHOU ${ }^{1,2}$, YIRAN CHEN $^{1,2}$, \\ GUIHAO KE ${ }^{1,2}$, HAO WEN ${ }^{1,2}$ and XIAOHUA WU ${ }^{1,2}$ \\ ${ }^{1}$ Department of Gynecologic Oncology, Fudan University Shanghai Cancer Center; ${ }^{2}$ Department of Oncology, \\ Shanghai Medical College, Fudan University, Shanghai 200032, P.R. China \\ Received February 18, 2016; Accepted July 27, 2017
}

DOI: $10.3892 / \mathrm{ol} .2017 .7040$

\begin{abstract}
Expression of eukaryotic initiation factor 4A1 (eIF4A1) following brachytherapy has been reported to predict improved radiosensitivity and tumor-specific survival in cervical cancer. Therefore, the present study investigated the function of eIF4A1 in cervical cancer and the mechanism by which eIF4A1 regulates cervical cancer radiosensitivity. It was determined that the downregulation of eIF4A1 in HeLa and SiHa cells notably attenuated cell proliferation, in addition to repressing cervical cancer migration and invasion, and promoting cell apoptosis. In vitro and in vivo studies have demonstrated that silencing eIF4A1 improves cervical cancer radiosensitivity. Detection of $\gamma-\mathrm{H} 2 \mathrm{AX}$ using western blot analysis at $0,0.5,1,6$ and $24 \mathrm{~h}$ following the exposure of cervical cancer cells to X-rays illustrated that eIF4A1-knockdown results in postponed radiation-induced DNA double strand break (DSB) repair. Overall, the results of the present study demonstrated that downregulated eIF4A1 improves cervical cancer radiosensitivity by delaying cancer cell DSB repair. In conclusion, the data indicated that eIF4A1 performs a vital role in cervical cancer progression and radiosensitivity. Therefore, eIF4A1 may be a potential therapeutic target in patients with cervical cancer.
\end{abstract}

\section{Introduction}

Although the incidence of cervical cancer has decreased due to more regular cytological screening programs and the success of human papillomavirus vaccinations, it remains the third most common type of gynecological cancer worldwide (1).

Correspondence to: Dr Xiaohua Wu, Department of Gynecologic Oncology, Fudan University Shanghai Cancer Center, 270 Dongan Road, Shanghai 200032, P.R. China

E-mail: docwuxh@hotmail.com

Key words: cervical cancer, radiosensitivity, eukaryotic initiation factor 4A1, DNA double strand break
The International Agency for Research on Cancer estimated there were 528,000 new cases and 266,000 deaths in 2012, and a total of $\sim 9 / 10(87 \%)$ of cervical cancer mortalities occur in less developed regions (2). At present, radiotherapy, as an adjuvant or primary treatment, remains the most common and effective therapeutic intervention for cervical cancer. Several international clinical trials have reported that adjuvant radiotherapy or concurrent chemoradiation therapy can improve disease-free survival and overall survival outcomes in patients with pathological risk factors for recurrence (3-5). However, radiotherapy ultimately fails in $>20 \%$ of patients with locally advanced cervical cancer (FIGO stage IB2-IVA), the main cause of which is radio-resistance $(6,7)$. Clinically, the identification and treatment of radio-resistant cervical cancer remains a challenge.

Eukaryotic initiation factor (eIF) $4 \mathrm{~F}$ is composed of ATP-dependent RNA helicase eIF4A1, 5' cap mRNA-binding protein eIF4E and the scaffolding protein eIF4G, which scans mRNAs through the 5' untranslated region (5'UTR), and unwinds the mRNA secondary structure to expose the translation initiation codon and initiates translation $(8,9)$. Assembly of the eIF4F complex is rate-limiting step for translation initiation. Increased eIF4F complex formation elevates the translation of all cap-dependent mRNAs, thereby increasing global protein synthesis rates. However, mRNAs vary widely in their inherent translatability, largely as a function of differences in the length and structure of their 5'UTRs. Cellular mRNAs that are the most sensitive to alterations in eIF4F complex formation include weak mRNAs, which are GC rich and highly-structured 5'UTRs $(8,9)$. c-Myc, vascular endothelial growth factor, ornithine decarboxylase and survivin typically encode growth and survival factors $(8,9)$. Therefore, eIF4A1 may perform an essential role in the translation of weak mRNAs, indicating that eIF4A1 is an important oncogenic protein. This has been verified by numerous prior studies (10-13). Our previous study (10) also revealed that eIF4A1 expression is associated with certain clinicopathological variables of cervical cancer, including the International Federation of Gynecology and Obstetrics (FIGO) stage (14), histological type, pelvic lymph node metastasis status, parametrial invasion and deep stromal invasion. In 
addition, the decreased expression of eIF4A1 following brachytherapy may predict improved radiosensitivity and tumor-specific survival. These findings indicate that eIF4A1 may be of importance in cervical cancer, particularly in cancer cell radiosensitivity. Therefore, the present study analyzed the function of eIF4A1 in cervical cancer and attempted to explore the underlying mechanisms.

\section{Materials and methods}

Cell lines and cell culture. The HeLa and SiHa cervical cancer cell lines and the $293 \mathrm{~T}$ cell line were obtained from the American Type Culture Collection (Manassas, VA, USA). Cells were maintained in Dulbecco's modified Eagle's medium (DMEM; Gibco; Thermo Fisher Scientific, Inc., Waltham, MA, USA) supplemented with $10 \%$ heat-inactivated fetal bovine serum (FBS; Gibco; Thermo Fisher Scientific, Inc.) and penicillin $(100 \mu \mathrm{g} / \mathrm{ml})$ and streptomycin $(100 \mathrm{U} / \mathrm{ml})$, and incubated in a humidified incubator at $37^{\circ} \mathrm{C}$ in an atmosphere containing $5 \% \mathrm{CO}_{2}$.

RNA interference and eIF4A1 downregulated cells. The two selected short hairpin RNA (shRNA/shR) sequences for eIF4A1 were as follows: P1 sense, 5'-CCGGGC CGTGTGTTTGATATGCTTACTCGAGTAAGCATATCA AACACACGGCTTTTTG-3' and antisense, 5'-AATTCA AAAAGCCGTGTGTTTGATATGCTTAC TCGAGTAAGC ATATCAAACACACGGC-3'; P2 sense, 5'-CCGGGCCGT AAAGGT GTGGCTATTACTCGAGTAATAGCCACACCT TTACGGCTTTTTG-3' and antisense, 5'-AATTCAAAA AGCCGTAAAGGTGTGGCTATTACTCGAGTAATAGCC ACACCTTTACGGC-3'. These sequences were synthesized by Sangon Biotech Co., Ltd. (Shanghai, China), annealed and ligated into the pLKO.1 lentiviral shRNA vector linearized by AgeI and EcoRI (New England Biolabs, Inc., Ipswich, MA, USA). eIF4A1 downregulated cells were established using the following process: The recombinant lentivirus with shR-eIF4A1 was produced by co-transfecting 293T cells with the plasmids, psPAX2 and pMD2.G using Lipofectamine ${ }^{\circledR} 2000$ transfection reagent (Invitrogen; Thermo Fisher Scientific, Inc.), according to the manufacturer's protocol. After transfection for $48 \mathrm{~h}$, Lentivirus-containing supernatants were centrifuged at $400 \mathrm{x} \mathrm{g}$ for $5 \mathrm{~min}$ at room temperature and filtered through a $0.45-\mu \mathrm{m}$ cellulose acetate filter (Merck $\mathrm{KGaA}$, Darmstadt, Germany), and stored at $4^{\circ} \mathrm{C}$. Subsequently, $\mathrm{SiHa}$ and HeLa cells which obtained $30 \%$ confluency were cultured in a humidified incubator at $37^{\circ} \mathrm{C}$ with $5 \% \mathrm{CO}_{2}$ with the shR-eIF4A1 lentivirus-containing supernatant, diluted with serum-free DMEM at a ratio of 1:1. After $24 \mathrm{~h}$, the culture medium was removed and fresh medium was added to the cells. Finally, $2 \mathrm{mg} / \mathrm{ml}$ puromycin (Sigma-Aldrich; Merck $\mathrm{KGaA}$ ) was added to the medium. Following antibiotic selection for 48 h, eIF4A1-downregulated cells (HeLa-shR1, 2; SiHa-shR1, 2) were obtained.

Cell proliferation assay. A Cell Counting kit-8 (CCK)- 8 (Dojindo Molecular Technologies, Inc., Kumamoto, Japan) was used to evaluate cell proliferation. The shR-eIF4A1-infected cells and parental cells were seeded at a density of 1,000 cells/well on a 96-well plate. After $6 \mathrm{~h}$ and 1,2, 3 and
4 days, $10 \mu$ l CCK- 8 reagent was added to each well and incubated for $2 \mathrm{~h}$ at $37^{\circ} \mathrm{C}$ with $5 \% \mathrm{CO}_{2}$. The absorbance at $450 \mathrm{~nm}$ was then measured using a Tecan Sunrise Microplate Reader (Tecan Group, Ltd., Männedorf, Switzerland) to determine the cell number.

Cell invasion and migration assays. The eIF4A1-downregulated cells and parental cells were resuspended in serum-free DMEM. Subsequently, the upper Transwell chambers (8-mm pore size; BD Biosciences, Franklin Lakes, USA) containing Matrigel coatings were seeded with 100,000 cells, which were cultured with serum-free medium. A total of 50,000 cells were added to the upper Transwell chambers without Matrigel coatings and cultured with serum-free medium. The lower chambers contained medium supplemented with $10 \%$ FBS. After $24 \mathrm{~h}$ of incubation, the non-migrated cells were gently removed with cotton swabs, and the migrated cells on the bottom surface of the membranes were fixed and then stained with $1 \%$ crystal violet in $100 \%$ ethanol for $15 \mathrm{~min}$ at room temperature. Cells were then visualized using an Olympus light microscope (Olympus Corporation, Tokyo, Japan) at magnification, $\mathrm{x} 20$. The invasive/migratory cells were counted from five random fields of view.

Cell apoptosis. Apoptosis was determined using an Annexin V and propidium iodide (PI) staining-based Fluorescein Isothiocyanate-Annexin V Apoptosis Detection kit (BD Biosciences) according to the manufacturer's protocol. The eIF4A1-downregulated cells and parental cells were seeded into a 6 -well plate $\left(2 \times 10^{5}\right.$ cells/well $)$ and incubated for $24 \mathrm{~h}$ at $37^{\circ} \mathrm{C}$ with $5 \% \mathrm{CO}_{2}$. Cells were then resuspended and labeled using the Apoptosis Detection kit, and the apoptotic cells were determined using a FACScan cytofluorometer from BD Biosciences (Franklin Lakes, NJ, USA) with Cell Quest software version 5.1 (BD Biosciences).

Cervical cancer radiosensitivity assay in vitro and in vivo. A cell colony formation assay was applied for cervical cancer cell radiosensitivity analyses. Exponential growth phase eIF4A1-downregulated cells and parental cells (200-8,000) were seeded onto 6-well plates. Following incubation for 6-8 h, the plates were irradiated with 137Cs (Nordion, Ottawa, ON, Canada). The dose rate was $1.25 \mathrm{~Gy} / \mathrm{min}$, with doses of $0,2,4,6,8$ Gy given in a single fraction. Following incubation at $37^{\circ} \mathrm{C}$ with $5 \% \mathrm{CO}_{2}$ for $10-13$ days, the cells were fixed and then stained with $1 \%$ crystal violet in $100 \%$ ethanol for $15 \mathrm{~min}$ at room temperature. Colonies containing $\geq 50$ cells were counted. The plating efficiency $(\mathrm{PE})=($ the number of clones/the number of planted cells) $\mathrm{x} 100 \%$, and the surviving fraction (SF) was the number of colonies formed/(the number of cells plated $x$ the plating efficiency) $(15,16)$.

The in vivo radiosensitivity assay was approved by the Department of Laboratory Animal Science, Fudan University (Shanghai, China). The mice were housed under controlled $12 \mathrm{~h}$ light-dark cycles, constant temperature $\left(22-24^{\circ} \mathrm{C}\right)$ and humidity (55-60\%), and were given sterilized food and tap water ad libitum. The mice were used when they were 6 -weeks and weighed $25 \mathrm{~g}$. SiHa-shR1 cells or $\mathrm{SiHa}$ cells (1) $10^{6} /$ mouse) were subcutaneous injected into the right thigh of the $32 \mathrm{BALB} / \mathrm{c}$ female nude mice (Shanghai SLAC 
Laboratory Animal Co., Shanghai, China). When tumors reached $8 \mathrm{~mm}$ in diameter ( 14 days post-injection), all mice were randomly divided into two groups. One group received radiation treatment (16 Gy with $6 \mathrm{MV}$ of X-rays), whilst the other group served as the controls. Tumor diameters were measured every 3 days for $\leq 37$ days to calculate the tumor volume (V) using the following equation $\mathrm{V}=\left(\mathrm{LxW}^{2}\right) \times 0.5$, where $\mathrm{L}$ was the length of the long side of the tumor and $\mathrm{W}$ was the length of the short side.

Western blot analysis. The cells were collected and then lysed with RIPA lysis buffer (1\% NP-40, 0.1\% SDS, $0.5 \%$ sodium deoxycholate, $150 \mathrm{mmol} / 1 \mathrm{NaCl}$ and $10 \mathrm{mmol} / 1$ Tris-HCl) containing 1/100 phenylmethanesulfonyl fluoride solution. The total protein concentration was determined using a BCA protein assay kit (Beyotime Institute of Biotechnology, Haimen, China). Aliquots $(30 \mu \mathrm{g})$ of each sample were separated by $12 \%$ polyacrylamide gel electrophoresis and transferred to PVDF membranes (EMD Millipore). The membranes were blocked with 5\% non-fat milk at room temperature for $2 \mathrm{~h}$. Subsequently, the membranes were probed with primary antibodies against eIF4A1 (1:1,000 dilution; cat no. T2192; Epitomics; Abcam, Cambridge, UK) or $\beta$-actin (1:2,000 dilution; cat no. 4967S; Cell Signaling Technology, Inc., Danvers, MA, USA) or $\gamma$-H2AX (1:1,000 dilution; cat no. 2577; Cell Signaling Technology, Inc.) in TBS-Tween-20 (TBST) containing 5\% non-fat milk (Sigma-Aldrich; Merck $\mathrm{KGaA}$, Darmstadt, Germany) at $4^{\circ} \mathrm{C}$ overnight, followed by three washes in TBST for 10 min per wash. Subsequently, the membranes were incubated with the goat anti-rabbit horseradish peroxidase conjugated-secondary antibody (1:3,000 dilution; cat no. ab97051; Abcam) for $1 \mathrm{~h}$ at room temperature. Immunoreactive bands were visualized using an enhanced chemiluminescence reaction (Pierce; Thermo Fisher Scientific, Inc.). $\beta$-actin was used as an internal control.

Statistical analysis. Data are presented as the mean \pm standard error. SPSS software (version 19.0 for Windows; IBM Corp., Armonk, NY, USA) was used for statistical analysis. The $\chi^{2}$ test, Fisher's exact test and Student's t-test were applied to assess statistical significance. All tests were two-sided, and $\mathrm{P}<0.05$ was considered to indicate a statistically significant difference.

\section{Results}

Downregulated eIF4A1 inhibits cervical cancer cell proliferation and migration, and promotes cell apoptosis. To assess the effects of eIF4A1 in cervical cancer cells, eIF4A1-downregulated cells (HeLa-shR1, 2; SiHa-shR1, 2) were established and western blotting was used to verify the success of the transfection and knockdown (Fig. 1A). A CCK-8 assay determined that the downregulation of eIF4A1 in HeLa and SiHa cells notably attenuated cell proliferation (Fig. 1B; $\mathrm{P}<0.001$ ). The effect of eIF4A1 on cervical cancer cell invasion was examined using a Matrigel-based invasion assay with a Transwell chamber. The number of HeLa-shR1, 2 and SiHa-shR1, 2 cells (Fig. 1C) that passed through the Matrigel basement membrane matrix was markedly decreased compared with the parental cells $(\mathrm{P}<0.001)$. Likewise, the migration ability of
HeLa and SiHa cells decreased significantly after the silence of eIF4A1 (Fig. 1D; P<0.001). However, flow cytometry revealed that HeLa-shR1, 2 and SiHa-shR1, 2 cells had a larger proportion of apoptotic cells than the parental cells (Fig. 1E; $\mathrm{P}<0.05)$. These results revealed that downregulated eIF4A1 markedly repressed cervical cancer cell viability and promote cell apoptosis.

Downregulation of eIF4A1 improves cervical cancer radiosensitivity in vitro and in vivo. Our previous study (10) demonstrated that the alteration of eIF4A1 expression in response to brachytherapy was associated with cervical cancer radiosensitivity. In the present study, a cervical cancer cell colony formation assay with radiation was conducted. As presented in Fig. 2A, decreased expression of eIF4A1 in $\mathrm{HeLa}$ and $\mathrm{SiHa}$ cells increased their radiosensitivity in vitro $(\mathrm{P}<0.05)$.

A tumorigenesis assay in nude mice was then performed, which revealed that the SiHa-shR1 cell tumor volumes following X-ray irradiation were significantly smaller than those formed by the parental cells (Fig. 2B; $\mathrm{P}<0.05$ ), indicating that the downregulation of eIF4A1 improved cervical cancer radiosensitivity.

Downregulation of eIF4A1 improves cervical cancer radiosensitivity by delaying cancer cell DSB repair. To disclose how decreased eIF4A1 expression improved cervical cancer cell radiosensitivity, DNA DSB repair, which measured by the expression of $\gamma-\mathrm{H} 2 \mathrm{AX}$, was examined. In the present study, the expression of $\gamma$-H2AX was detected by western blot analysis at $0,0.5,1,6$ and $24 \mathrm{~h}$ following irradiation of the cancer cells. As presented in Fig. 2C, 0.5 and $1 \mathrm{~h}$ following irradiation, which means a period of DNA DSB, the band concentration of $\gamma$-H2AX between eIF4A1 downregulation and parental cells were all at a high level, and no significant differences were observed. These results indicated that eIF4A1 has no notable effect on the initial level of radiation-induced DSB. However, at 6 and 24 h post-irradiation, $\gamma$-H2AX protein levels in eIF4A1 downregulated cells were markedly increased than in parental cells, which illustrated that eIF4A1-knockdown, causes the inhibition of radiation-induced DNA DSB repair. Overall, it was considered that downregulated eIF4A1 improves cervical cancer cell radiosensitivity by delaying cell DSB repair.

\section{Discussion}

eIF4A1 is a canonical DEAD-box helicase that exhibits ATP-dependent RNA helicase activity in mRNA translation (17-19), particularly for oncoproteins or proteins implicated in cell growth, death or proliferation $(20,21)$. Elevated expression of eIF4A1 has been reported in primary hepatocellular carcinomas, melanoma cell lines and congenital melanocytic nevi $(11,12)$. Furthermore, targeting eIF4A1 has been determined to reverse lymphoma cancer cell chemo-resistance (13). In our previous study (10), it was demonstrated that eIF4A1 overexpression promotes cervical cancer. In the present study, downregulated eIF4A1 was revealed to inhibit cervical cancer cell proliferation and induce apoptosis in vitro. In addition, SiHa-shR1 cells generated xenografts were statistically smaller than their parental SiHa cells (Fig. $2 \mathrm{~B}$; $\mathrm{P}<0.05$ ). These 

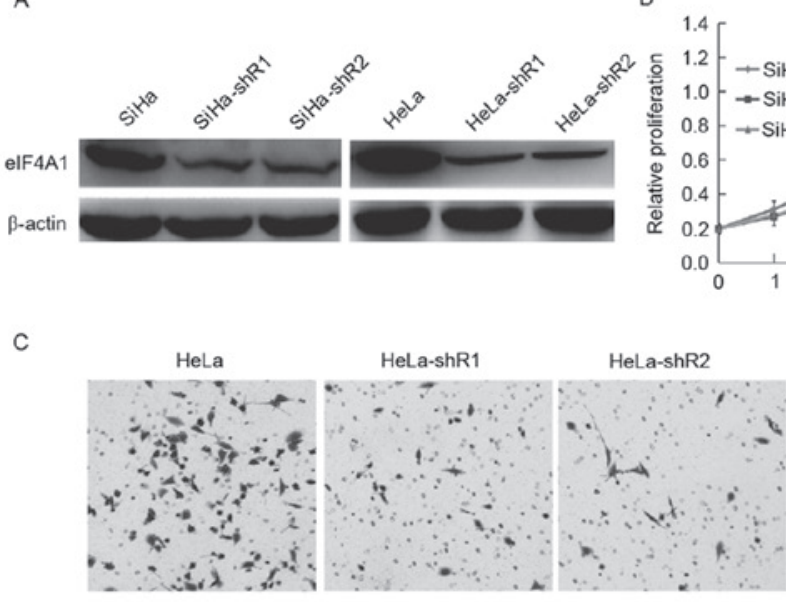

$\mathrm{SiHa}$
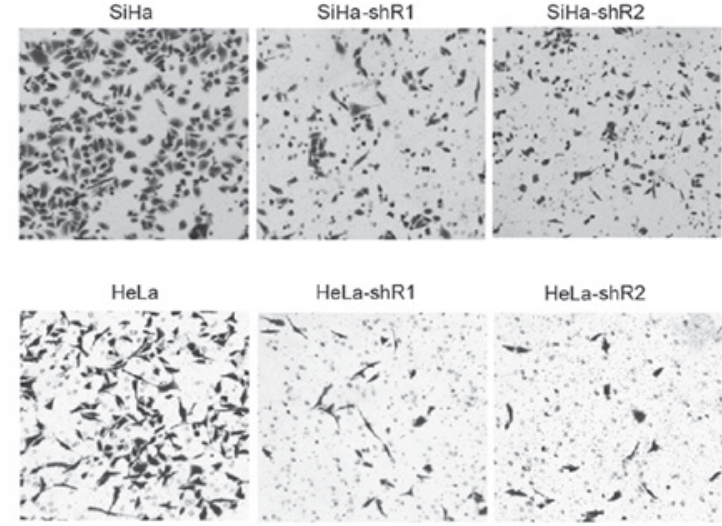

$\mathrm{SiHa}$

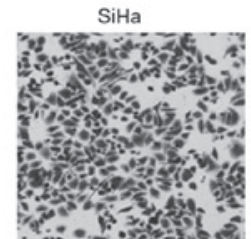

SiHa-shR1

SiHa-shR2

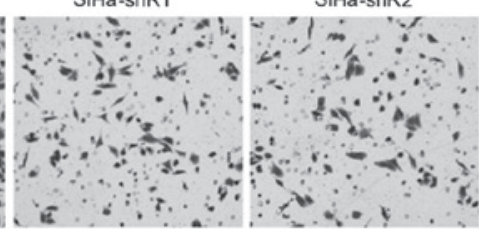

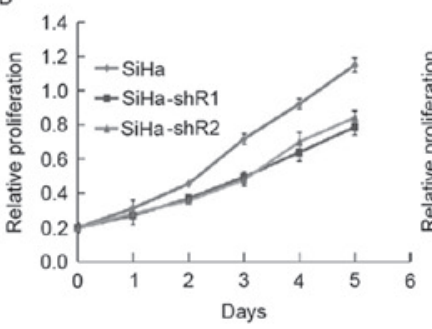

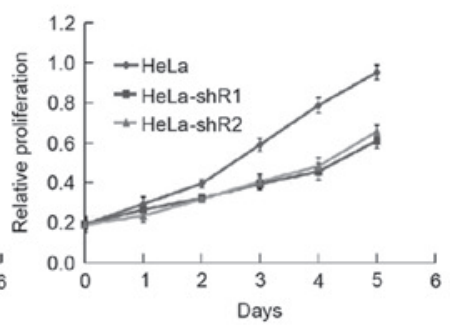

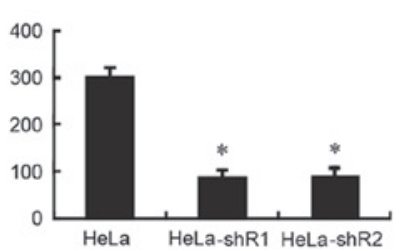
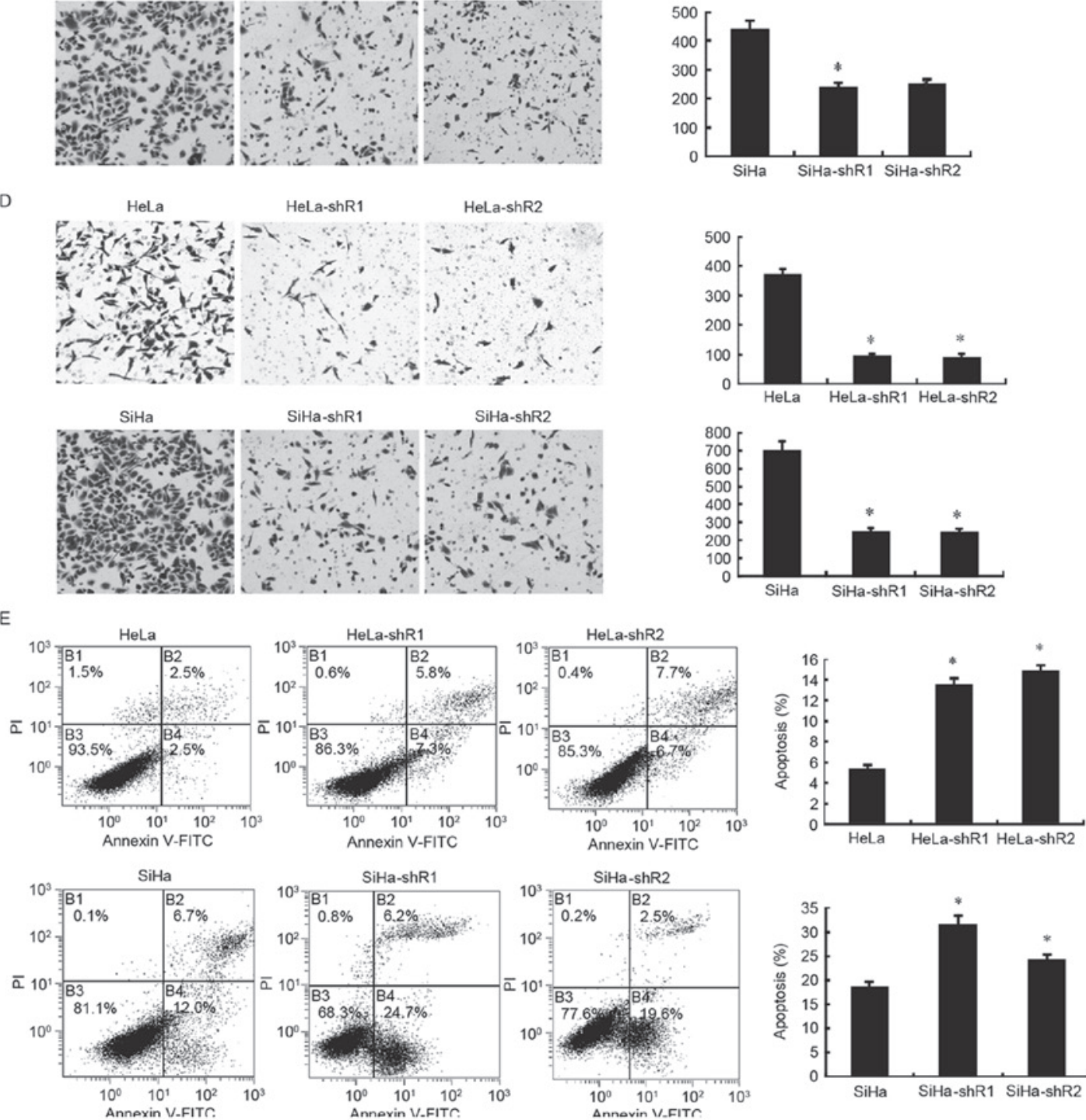

Figure 1. Downregulation of eIF4A1 in cervical cancer cells significantly affected cell proliferation, viability and apoptosis. (A) Construction and validation of downregulated eIF4A1 in HeLa and SiHa cell lines. pLKO.1-TRC cloning vector and two pairs of shRNA for eIF4A1 were used to construct stable-knockdown eIF4A1 cells. Western blot analysis revealed that eIF4A1 was significantly downregulated in cervical cancer cells (HeLa-shR1, 2; SiHa-shR1, 2). (B) Effects of eIF4A1-knockdown on cervical cancer cell proliferation. Downregulated eIF4A1 inhibited HeLa and SiHa cell growth, as measured by a Cell Counting kit-8 assay. This inhibition effect was significant by day $5(\mathrm{P}<0.001)$. (C) The effect of eIF4A1 on cervical cancer cell invasion was examined using a Matrigel-based invasion assay with Transwell chambers. The number of HeLa-shR1, 2 and SiHa-shR1, 2 cells that passed through the Matrigel basement membrane matrix was markedly lower compared with the parental cells (P<0.001). (D) The effect of eIF4A1 on cervical cancer cell migration was examined using a Transwell chamber assay. The migration ability of HeLa and SiHa cells decreased significantly after the silence of eIF4A1 (P<0.001). (E) Flow cytometric analysis of cells stained with Annexin V/PI. The percentages of cells in each quadrant are indicated. Knockdown of eIF4A1 significantly induced apoptosis in HeLa and SiHa cells ( $\mathrm{P}<0.05)$. (Q1, necrotic cells; Q2, cells in late apoptosis; Q3, normal cells; and Q4, cells in early apoptosis.). PI, propidium iodide; FITC, fluorescein isothiocyanate; eIF4A1, eukaryotic initiation factor 4A1; shR, short hairpin RNA. "P<0.05 vs. the control. 
A

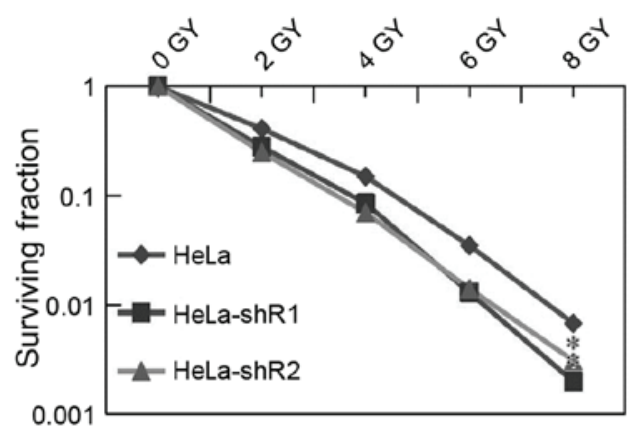

B

$\mathrm{SiHa}$

SiHa-shR1

SiHa+X-ray

SiHa-shR1+X-ray


$0 \mathrm{P} \mathrm{O}$

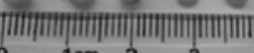

B1
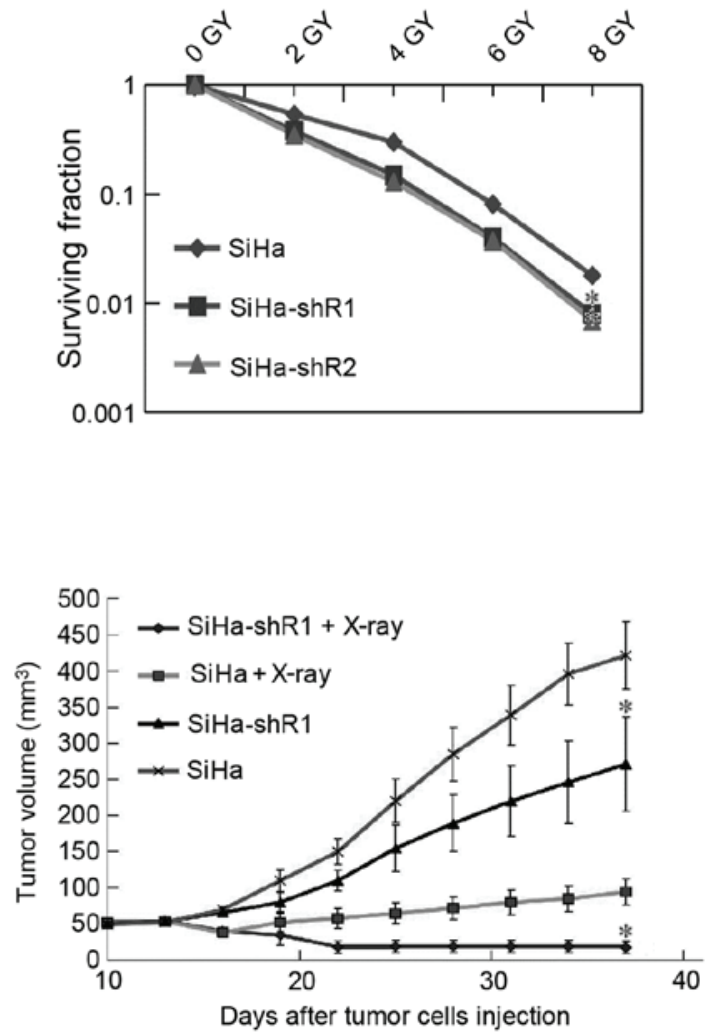

B2

C

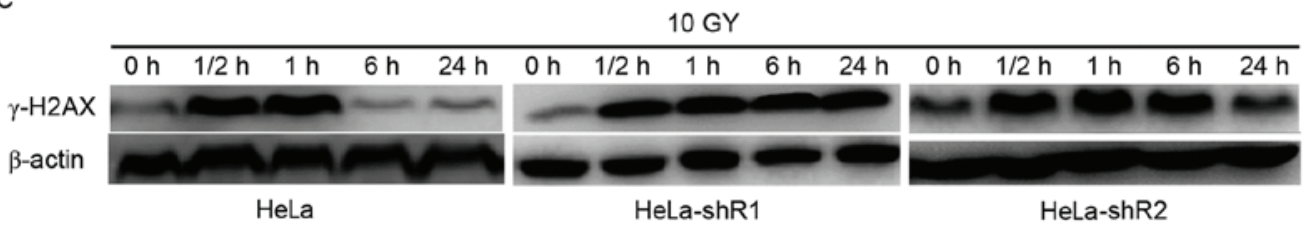

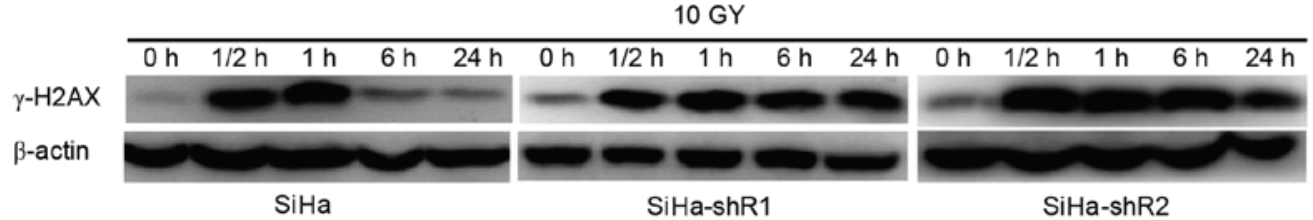

Figure 2. Downregulated eIF4A1 enhanced cervical cancer cell radiosensitivity in vitro and in vivo. (A) Decreased eIF4A1 enhanced HeLa and SiHa cell radiosensitivity; this effect became apparent when exposed to 4, 6 and 8 Gy $\mathrm{X}$-ray $(\mathrm{P}<0.05)$. These experiments were repeated three separate times. (B) The tumor volumes in SiHa-shR1 group were significantly smaller than those in $\mathrm{SiHa}$ group $(\mathrm{P}<0.05)$. A total of 1x10 ${ }^{6}$ cells $(\mathrm{SiHa}-\mathrm{shR} 1$ or $\mathrm{SiHa}$-shR1) were subcutaneously injected into the right thigh of each 6-week-old BALB/C nude mice (16:16). When the diameter of the tumors reached $8 \mathrm{~mm}$, mice bearing either SiHa-shR tumors or $\mathrm{SiHa}$ tumors were randomly divided into two groups. One group received irradiation treatment (16 Gy with 6 MV X-rays), while the other group served as the control. Tumor sizes were measured every 3 days. (C) eIF4A1-knockdown resulted in the inhibition of radiation-induced DNA double strand break repair. At $0,0.5$ and $1 \mathrm{~h}$ following exposure to radiation, no significant difference of $\gamma$-H2AX protein was detected between the eIF4A1-downregulated cells and the parental cells. However, at 6 and $24 \mathrm{~h}$ post-irradiation, the $\gamma$-H2AX protein levels in eIF4A1-downregulated cells were significantly greater than those in the parental cells. ${ }^{\mathrm{P}}<0.05$ vs. the control. eIF4A1, eukaryotic initiation factor $4 \mathrm{~A} 1$; shR, short hairpin RNA.

results confirmed that eIF4A1 promotes cervical cancer and may be used as a therapeutic target.

The clinical findings from our previous study (10) also indicated that eIF4A1 expression is associated with cervical cancer lymph node metastasis. Ji et al (22) reported that eIF4A1 is an early marker of distant metastasis of non-small cell lung cancer. Therefore, Transwell experiments were performed in vitro to verify this association. As predicted, the results of the current study revealed that the invasion and migration abilities of eIF4A1 downregulated cells were significantly suppressed compared with the parental cells. These findings indicated that eIF4A1 performs an important role in cervical cancer viability.

To determine the association between eIF4A1 expression and cervical cancer radiosensitivity, a colony formation assay was conducted with $\mathrm{X}$-ray radiation in vitro and in vivo. 
Compared with parental cells, the colony-forming ability of eIF4A1 downregulated cells was significantly lower (Fig. 2A; $\mathrm{P}<0.05)$. Furthermore, studies in vivo have also observed that the radiosensitivity of $\mathrm{SiHa}-\mathrm{sh} \mathrm{R}$ cells was markedly enhanced. Thus, to the best of our knowledge, the current study confirmed for the first time that the reduced expression of eIF4A1 improved cervical cancer radiosensitivity, thus presenting a potential novel target for cervical cancer therapy.

Radiation is known to cause damage to DNA, including base damage, DNA strand breaks (single strand breaks and DSB) and DNA strand cross-linking (23-25). Base damage, DNA strand cross-linking and single strand breaks are often repaired successfully, however, DSB repair tends to result in gene mutations or genomic instability (26-28). It has been reported that $\gamma-\mathrm{H} 2 \mathrm{AX}$ forms at the DSB site in response to DNA damage caused by ionizing radiation, and that each foci of $\gamma$-H2AX corresponds to one DSB (29-34). Subsequently, DSB repair would occur within $30 \mathrm{~min}, 75 \%$ of which would fade away within $5 \mathrm{~h}$, in which an almost complete $\gamma$-H2AX loss is estimated to occur within 7-8 h (35-38). Therefore, in the present study, western blot analysis was used to detect the expression of $\gamma-\mathrm{H} 2 \mathrm{AX}$ within $24 \mathrm{~h}$. For the parental HeLa and SiHa cells, $\gamma$-H2AX expression was barely detectable within $6 \mathrm{~h}$, suggesting that DSB repair was successful. However, for eIF4A1 downregulated cells, $\gamma$-H2AX remained at a high level at $6 \mathrm{~h}$ and at $24 \mathrm{~h}$, which indicated postponed DSB repair. Therefore, it was concluded that downregulated eIF4A1 increased cervical cancer radiosensitivity by delaying cancer cell DSB repair. However, the mechanism by which downregulated eIF4A1 delays DSB repair remains under investigation.

In conclusion, the present study confirmed that downregulated eIF4A1 significantly inhibited cervical cancer cell proliferation and viability, and induced cell apoptosis. In addition, the present study provided evidence that cervical cancer radiosensitivity may be enhanced by downregulated eIF4A1 due to delayed cancer cell DSB repair, indicating that eIF4A1 may be a promising target for increasing cervical cancer radiosensitivity.

\section{References}

1. Siegel R, Naishadham D and Jemal A: Cancer statistics, 2013. CA Cancer J Clin 63: 11-30, 2013.

2. Ferlay J, Soerjomataram I, Dikshit R, Eser S, Mathers C, Rebelo M, Parkin DM, Forman D and Bray F: Cancer incidence and mortality worldwide: sources, methods and major patterns in GLOBOCAN 2012. Int J Cancer 136: E359-E386, 2015.

3. Sedlis A, Bundy BN, Rotman MZ, Lentz SS, Muderspach LI and Zaino RJ: A randomized trial of pelvic radiation therapy versus no further therapy in selected patients with stage IB carcinoma of the cervix after radical hysterectomy and pelvic lymphadenectomy: A gynecologic oncology group study. Gynecol Oncol 73: 177-183, 1999.

4. Monk BJ, Wang J, Im S, Stock RJ, Peters WA III, Liu PY, Barrett RJ II, Berek JS, Souhami L, Grigsby PW, et al: Rethinking the use of radiation and chemotherapy after radical hysterectomy: A clinical-pathologic analysis of a gynecologic oncology group/southwest oncology group/radiation therapy oncology group trial. Gynecol Oncol 96: 721-728, 2005.

5. Rotman M, Sedlis A, Piedmonte MR, Bundy B, Lentz SS, Muderspach LI and Zaino RJ: A phase III randomized trial of postoperative pelvic irradiation in Stage IB cervical carcinoma with poor prognostic features: Follow-up of a gynecologic oncology group study. Int J Radiat Oncol Biol Phys 65: 169-176, 2006.
6. Eifel PJ, Winter K, Morris M, Levenback C, Grigsby PW, Cooper J, Rotman M, Gershenson D and Mutch DG: Pelvic irradiation with concurrent chemotherapy versus pelvic and para-aortic irradiation for high-risk cervical cancer: An update of radiation therapy oncology group trial (RTOG) 90-01. J Clin Oncol 22: 872-880, 2004.

7. Legge F, Chiantera V, Macchia G, Fagotti A, Fanfani F, Ercoli A, Gallotta V, Morganti AG, Valentini V, Scambia G and Ferrandina G: Clinical outcome of recurrent locally advanced cervical cancer (LACC) submitted to primary multimodality therapies. Gynecol Oncol 138: 83-88, 2015.

8. De Benedetti A and Graff JR: eIF4E expression and its role in malignancies and metastases. Oncogene 23: 3189-3199, 2004

9. Graff JR, Konicek BW, Carter JH and Marcusson EG: Targeting the eukaryotic translation initiation factor 4E for cancer therapy. Cancer Res 68: 631-634, 2008.

10. Liang S, Zhou Y, Chen Y, Ke G, Wen H and Wu X: Decreased expression of EIF4A1 after preoperative brachytherapy predicts better tumor-specific survival in cervical cancer. Int J Gynecol Cancer 24: 908-915, 2014.

11. Shuda M, Kondoh N, Tanaka K, Ryo A, Wakatsuki T, Hada A, Goseki N, Igari T, Hatsuse K, Aihara T, et al: Enhanced expression of translation factor mRNAs in hepatocellular carcinoma. Anticancer Res 20: 2489-2494, 2000.

12. Eberle J, Krasagakis $\mathrm{K}$ and Orfanos CE: Translation initiation factor eIF-4A1 mRNA is consistently overexpressed in human melanoma cells in vitro. Int J Cancer 71: 396-401, 1997.

13. Bordeleau ME, Robert F, Gerard B, Lindqvist L, Chen SM, Wendel HG, Brem B, Greger H, Lowe SW, Porco JA Jr and Pelletier J: Therapeutic suppression of translation initiation modulates chemosensitivity in a mouse lymphoma model. J Clin Invest 118: 2651-2660, 2008.

14. Pecorelli S: Revised FIGO staging for carcinoma of the vulva, cervix, and endometrium. Int J Gynaecol Obstet 105: 103-104, 2009.

15. Puck TT and Marcus PI: Rapid method for viable cell titration and clone production with HELA cells in tissue culture: The use of X-irradiated cells to supply conditioning factors. Proc Natl Acad Sci USA 41: 432-437, 1955.

16. Puck TT and Marcus PI: Action of X rays on mammalian cells. J Exp Med 103: 653-666, 1956.

17. Linder P, Tanner NK and Banroques J: From RNA helicases to RNPases. Trends Biochem Sci 26: 339-341, 2001.

18. Cordin O, Banroques J, Tanner NK and Linder P: The DEAD-box protein family of RNA helicases. Gene 367: 17-37, 2006.

19. Pyle AM: Translocation and unwinding mechanisms of RNA and DNA helicases. Annu Rev Biophys 37: 317-336, 2008.

20. Abdelhaleem M: Do human RNA helicases have a role in cancer? Biochim Biophys Acta 1704: 37-46, 2004.

21. Kozak M: An analysis of 5'-noncoding sequences from 699 vertebrate messenger RNAs. Nucleic Acids Res 15: 8125-8148, 1987.

22. Ji P, Diederichs S, Wang W, Böing S, Metzger R, Schneider PM, Tidow N, Brandt B, Buerger H, Bulk E, et al: MALAT-1, a novel noncoding RNA, and thymosin beta4 predict metastasis and survival in early-stage non-small cell lung cancer. Oncogene 22: 8031-8041, 2003

23. Painter RB: DNA damage and repair in eukaryotic cells. Genetics 78: 139-148, 1974.

24. O'Neill P and Wardman P: Radiation chemistry comes before radiation biology. Int J Radiat Biol 85: 9-25, 2009.

25. Nocentini S: Rejoining kinetics of DNA single- and double-strand breaks in normal and DNA ligase-deficient cells after exposure to ultraviolet $\mathrm{C}$ and gamma radiation: an evaluation of ligating activities involved in different DNA repair processes. Radiat Res 151: 423-432, 1999

26. Jeggo PA and Löbrich M: How cancer cells hijack DNA double-strand break repair pathways to gain genomic instability. Biochem J 471: 1-11, 2015.

27. Iliakis G, Wang H, Perrault AR, Boecker W, Rosidi B, Windhofer F, Wu W, Guan J, Terzoudi G and Pantelias G: Mechanisms of DNA double strand break repair and chromosome aberration formation. Cytogenet Genome Res 104: 14-20, 2004.

28. Mladenov E and Iliakis G: Induction and repair of DNA double strand breaks: The increasing spectrum of non-homologous end joining pathways. Mutat Res 711: 61-72, 2011.

29. Sánchez-Flores M, Pásaro E, Bonassi S, Laffon B and Valdiglesias V: $\gamma \mathrm{H} 2 \mathrm{AX}$ assay as DNA damage biomarker for human population studies: Defining experimental conditions. Toxicol Sci 144: 406-413, 2015. 
30. Hamer G, Roepers-Gajadien HL, van Duyn-Goedhart A Gademan IS, Kal HB, van Buul PP and de Rooij DG: DNA double-strand breaks and gamma-H2AX signaling in the testis. Biol Reprod 68: 628-634, 2003.

31. Paull TT, Rogakou EP, Yamazaki V, Kirchgessner CU, Gellert M and Bonner WM: A critical role for histone $\mathrm{H} 2 \mathrm{AX}$ in recruitment of repair factors to nuclear foci after DNA damage. Curr Biol 10 $886-895,2000$

32. Sedelnikova OA, Rogakou EP, Panyutin IG and Bonner WM: Quantitative detection of (125)IdU-induced DNA double-strand breaks with gamma-H2AX antibody. Radiat Res 158: 486-492, 2002.

33. Pilch DR, Sedelnikova OA, Redon C, Celeste A, Nussenzweig A and Bonner WM: Characteristics of gamma-H2AX foci at DNA double-strand breaks sites. Biochem Cell Biol 81: 123-129, 2003.

34. Rogakou EP, Boon C, Redon C and Bonner WM: Megabase chromatin domains involved in DNA double-strand breaks in vivo. J Cell Biol 146: 905-916, 1999.

35. Nazarov IB, Smirnova AN, Krutilina RI, Svetlova MP, Solovjeva LV, Nikiforov AA, Oei SL, Zalenskaya IA, Yau PM, Bradbury EM and Tomilin NV: Dephosphorylation of histone gamma-H2AX during repair of DNA double-strand breaks in mammalian cells and its inhibition by calyculin A. Radiat Res 160: 309-317, 2003.
36. Svetlova M, Solovjeva L, Nishi K, Nazarov I, Siino J and Tomilin N: Elimination of radiation-induced gamma-H2AX foci in mammalian nucleus can occur by histone exchange. Biochem Biophys Res Commun 358: 650-654, 2007.

37. Solovjeva LV, Pleskach NM, Firsanov DV, Svetlova MP, Serikov VB and Tomilin NV: Forskolin decreases phosphorylation of histone H2AX in human cells induced by ionizing radiation. Radiat Res 171: 419-424, 2009.

38. Löbrich M, Shibata A, Beucher A, Fisher A, Ensminger M, Goodarzi AA, Barton O and Jeggo PA: gammaH2AX foci analysis for monitoring DNA double-strand break repair: Strengths, limitations and optimization. Cell Cycle 9: 662-669, 2010. 